Indexaciones: Repositorio de Revistas UCR, DIALNET, Latindex, REDALYC Directorio y recolector de recursos digitales del Ministerio de Cultura de España, Directory of Open Access Journals. Diálogos Revista Electrónica de Historia ISSN 1409-469X. Número especial 2008. Dirección web: http://historia.fcs.ucr.ac.cr/dialogos.htm

\title{
Las formas de liberación de los africanos en la Audiencia de Guatemala, siglos XVI y XVII: el caso del mulato Hernando Díaz
}

\author{
Juan Pablo Peña Vicenteño
}

Investigador del Proyecto Afroamérica. La Tercera Raíz del Programa Universitario México Nación Multicultural (PUMC) adscrito a la Coordinación de Humanidades de la Universidad Nacional Autónoma de México (UNAM).

Maestrante del Posgrado en Estudios Latinoamericanos de la UNAM. 


\section{Introducción}

Los esclavos africanos en el Nuevo Mundo no fueron entes pasivos, por lo contrario, estaban en búsqueda de su libertad, sea de manera transgresiva o bien siguiendo procesos jurídicos para obtenerla, como las cartas que otorgaban sus amos, las cuales eran llamados horros. Los casos aquí presentados fueron obtenidos a partir de la localización, paleografía y análisis de diversos documentos que forman parte del acervo del Archivo General de Centro América (AGCA) ubicado en la ciudad capital de Guatemala.

Se mencionan a los cimarrones, a los horros pero lo que se pretende enfatizar es el caso del “Pleito entre Hernando Díaz, mulato, contra Diego Ordóñez de Villaquirán”, el primero pide su libertad a través de un juicio que, por el grosor del legajo y lo interesante que ofrece dicho manuscrito, fue motivo de su estudio y análisis. Si bien repaso las diferentes formas de liberación me detendré detalladamente en el juicio ya mencionado.

\section{Cimarronaje}

Los esclavos que huían de las haciendas eran considerado cimarrones, en el caso de la Audiencia de Guatemala se sabe que los malos tratos, las injusticias cometidas y la idea de liberación, fueron factores que determinaron la huida de los esclavos al orden colonial. No se sabe con certeza desde qué momento los esclavos empezaron a fugarse hacia los montes o lugares lejanos de los poblados donde estaban esclavizados, pero es posible que haya sido desde los primeros años del siglo XVI. En 1540, Carlos V envió una cédula en septiembre de ese año, en la que disponía que las autoridades debían pregonar que todo aquel esclavo que estuviera "alzado de su amo" regresara por su voluntad sin recibir ningún castigo ${ }^{1}$.

Lo más seguro es que los esclavos no hicieran caso de estas órdenes o ni siquiera llegaran a enterarse. Además, en 1548 se informa de la primera insurrección en San Pedro Sula. Allí, los esclavos estuvieron a punto de tomar el poblado, pero la guardia del puerto de Omoa tomó parte y restableció el orden. Más adelante, el presidente de la Audiencia, López de Cerrato fusiló al líder de éste movimiento. El rey aprobó la acción tomada por el presidente. ${ }^{2}$

Los cimarrones fueron una fuerte problemática para los pobladores de la Audiencia de

1 Ofelia Calderón, El negro en Guatemala durante la época colonial. Tesis de licenciatura. Guatemala, Universidad de San Carlos, 1973, 67.

$2 \quad$ AGCA, A1.23, Leg. 4575, Fol. 103, Año 1548. 
Guatemala, ya que continuamente los mercaderes se quejaban de los robos cometidos por ellos en los caminos. En 1571, Felipe II tomó parte de los informes en los que se indicaban las pérdidas de los comerciantes; ordenó que se hiciera todo lo posible para capturar a los cimarrones; y aconsejaba que se nombraran capitanes con experiencia para dirigir las cuadrillas que buscarían a los exesclavos.

Los gastos para estas expediciones deberían de cubrirse con una quinta parte de la Real Hacienda y la parte restante sería pagada por los vecinos, comerciantes y todos aquellos que se beneficiarían de esta empresa. Sin embargo, al término del siglo XVI no se había logrado el cometido.

En 1619, Felipe III ordenó que las autoridades tomaran medidas más drásticas, pidiendo que se castigara a los líderes de los alzados y que a éstos se les volviera a poner en esclavitud y servidumbre. Lo anterior se refleja en muchos documentos que existen, sobre todo en la región de Huatulco y sus cercanías, así como en la provincia de Antequera, Oaxaca. ${ }^{3}$

No obstante, la libertad fue adquirida no sólo por la huida de los esclavos, también se dio de forma legal, ya sea consiguiendo cédulas, o bien por cartas de los amos, a lo que se llamo horro o alforría. Algunos de estos libertos pudieron insertarse en la vida colonial, pero otros tuvieron muchos conflictos para hacerlo, por lo que en varias ocasiones volvieron a ser esclavizados. Sin embargo, los que consiguieron integrarse llegaron a poseer bienes y a tener un mayor rango en la vida económica y social, aunque nunca política.

\section{Horros}

Los esclavos horros son aquellos a los que se su amo les otorga la libertad. En algunos casos tenían que pagar la cantidad por la que fueron comprados o bien sólo dar la cantidad estipulada por el amo para poderles otorgar una cédula. Los esclavos juntaban el dinero requerido para su libertad trabajando como asalariados, es decir, eran alquilados para realizar alguna oficio por el cual su amo recibía una paga, y a su vez el trabajador se quedaba con un porcentaje menor. El dinero recaudado servía, en muchos casos, para pagar su libertad. Existen varias evidencias que corroboran la existencia de negros horros y la manera en como lograban su libertad por medio de este proceso.

3 AGN, Ramo Tierras, Vol. 2964, Exp. 257, Fojas 3. 
Hay información acerca de la participación de un negro horro en una de las batallas de conquista que se gestó en la región de Aguacatenango, en el peñón llamado Quetzaltepeque, en la provincia de Chiapa para el año de 1528. Al parecer la batalla estuvo muy reñida y no había manera de contrarrestar a los combates de los indígenas que estaban fortificados en ese peñón. Tres hombres fueron los que lograron tomar la fortaleza para vencer a los rebeldes. Uno de ellos fue un tal Villaseñor, otro Cristóbal de Morales y el tercero fue un negro, de quien no se especifica su nombre. ${ }^{4}$

El obispo Fray Tomás Casillas, en 1568, redacta su testamento en el cual da informes de sus bienes que tiene en la iglesia de Santo Domingo. Entre estos bienes se encuentran varios esclavos: Antón, Hernando Sebastián, María, Marcos y Miguelico 5 .

El esclavo Marcos, propiedad de Francisco Hidalgo, fue adquirido en doscientos diez pesos por el sacerdote, pero el vendedor reclama una cantidad que no ha sido pagada. El obispo pide que se pague el valor del esclavo a los herederos del antiguo dueño, pues Francisco Hidalgo ya ha muerto. El escrito continúa y Fray Tomás Casillas informa que deja horro a dicho esclavo, al igual que a Miguelico, sin mencionar que deben pagar el dinero por el cual fueron adquiridos. Aunque ya se mencionó que Marcos fue adquirido por doscientos diez tostones, en el caso de Miguelico el fraile no proporciona la cantidad por la cual fue adquirido. Este documento es muy singular ya que arroja datos sobre cómo los esclavos eran liberados, en la mayoría de las ocasiones por sus buenos servicios.

Para cotejar la información anterior, se puede ver que en 1602 se extiende una carta de libertad a María, negra de setenta años, esclava de Francisco Beltrán, un vecino de la ciudad de Guatemala, anteriormente había sido esbclava de Isabel Godínez, quien la obtuvo por herencia o dote y posteriormente la vendió al prior del convento de Santo Domingo, Alonso de Vildes la compró a este convento y de él la obtuvo Beltrán. La carta dice lo siguiente:

Por esta presente carta que horro y liberto a la dicha María negra de la sujeción y cautiverio en que a estado y esta. ${ }^{6}$

Era muy común que los esclavos estuvieran en manos de varios amos, en el caso de María se demuestra esta movilidad. Su libertad fue muy tardía y es posible que no pudiera

$4 \quad$ Gudrun Lenkersdorf, Génesis histórica de Chiapas. 1522-1532, el conflicto entre Portocarrero y Mazariegos, México, UNAM, 2001, 209.

5 Boletín No. 1 del Archivo Histórico Diocesano, San Cristóbal de las Casas, Chiapas,1981.

6 AGCA, A1.20, Legajo 430, Expediente 10365, Año 1602. 
llegar a tener bienes ni otras ventajas que obtenía al ser libre; sin embargo es interesante que después de sus "buenos servicios” se le otorgara la libertad. Se puede pensar que al esclavista ya no le servía de mucho la esclava y por ello la liberó, pues ya no estaba en edad de productividad laboral y además así se evitaba los gastos de manutención, por lo que prefirió horrarla.

\section{El proceso de Hernando Díaz de la Reguera}

Aunque los medios para obtener la libertad fueron diversos, los casos obtenidos por medio de procesos jurídicos fueron muy pocos, pues eran costosos y el esclavo no contaba con los medios suficientes para solventar los juicios. No obstante, en el Archivo General de Centroamérica se localizó un documento referente a un proceso sobre la petición de libertad de un mulato esclavo. $^{7}$

El proceso fue muy largo, tuvo una duración de tres años, de 1589 a 1591 . El manuscrito consta de una carátula, un testamento de 4 fojas, una introducción de 3 fojas, 57 fojas numeradas y 21 fojas de autos. Luego de realizar la paleografía y estudiar detenidamente el documento, se obtuvo información muy valiosa no sólo de la forma de liberación del esclavo, sino de las relaciones interculturales, es decir de cómo se integró el africano con otras culturas que convivían en la Colonia centroamericana, dicho de otro modo: los procesos de africanización tanto del indígena como del español. En este apartado veremos la interculturalidad entre españoles y africanos y cómo fue su interrelación con sus amos.

El proceso, en su mayor parte, fue llevado en la ciudad de San Salvador, pues los actores principales eran vecinos de esa ciudad. Sin embargo, más adelante el caso fue trasladado a la corte de la Audiencia de Guatemala, con sede en la ciudad de Santiago de los Caballeros, aunque también estuvo implicada la Ciudad Real de Chiapa.

El juicio, como dice la carátula, trata de un pleito entre Hernando Díaz, mulato, y Diego Ordóñez de Villaquirán, vecino de Ciudad Real de Chiapa. Ambos cuentan con un defensor, lo cual hace suponer que un esclavo podía contar con ese privilegio. El documento, en su primera parte, está fechado en 1591; sin embargo, a lo largo del manuscrito se van narrando varios escenarios que sirven para reconstruir los hechos, mismos que se desarrollaron en diferentes años.

7 AGCA, A1.1, Legajo 302, Expediente 2062, Año 1591. 
En primera instancia, se cuenta con un testamento de Gómez Díaz de la Reguera, un encomendero importante y de los más ricos de la provincia de San Salvador más específico de la Villa de Trinidad, según Murdo Macleod. Para el año de 1550, este personaje tenía ingresos anuales de alrededor de 1,500 pesos, y al parecer poseía una concesión de tierras otorgada por el presidente de la Audiencia en turno, Alonso Maldonado. ${ }^{8}$ La principal fuente económica de Gómez Díaz eran los sembradíos de cacao, los ingenios de azúcar y las estancias ganaderas, pues todo ello se menciona en el documento. El encomendero estaba casado con Isabel de Costilla, con quien tuvo una hija llamada Aldonça Barrientos Costilla. En el testamento los bienes se le otorgan a Diego Ordóñez de Villaquirán, esposo de doña Aldonça.

En el juicio se anota que Hernando Díaz es hijo de Diego Díaz de la Reguera, hermano de Gómez Díaz de la Reguera, y que fue encargado a Isabel de Costilla para su cuidado. La madre de Hernando es una negra que en 1587 contaba con 33 años.

Giromar, la madre del mulato, llegó directamente de Angola, era una negra "bozal” cómo se le conocía a los esclavos nacidos en África. A su llegada fue adquirida por Gaspar de Cepeda quien después la regaló a la familia Díaz de la Reguera. Isabel Costilla se hizo cargo de su sobrino, es decir, Hernando Díaz, quien fue criado como libre. La negra, llamada Giromar, tuvo dos hijos, uno de ellos es Hernando de 15 años y una "negrita” llamada Marina de 7 años. Los tres, madre e hijos, fueron entregados como dote de Aldonça.

Se sabe que la negra era esclava de Aldonça porque fue otorgada en dote a Diego Ordóñez junto con 12.000 pesos en el momento en que contrajeron matrimonio. Sin embargo, en el documento se menciona que Gómez Díaz de la Reguera tenía una deuda de dos mil pesos de oro de minas con Diego Ordóñez de Villaquirán. Los 12.000 pesos de la dote no contemplaban la deuda, la cual fue acordada en pagarse a plazos.

Al realizarse el matrimonio, Ordóñez adquiere las propiedades que se otorgaron por herencia a Aldonça, entre ellas una estancia ganadera en la que el mulato Hernando trabajaba y servía. Entre los esclavos africanos se encontraban una negra llamada Bartola, Juana Malaber [sic] con una hija, Melchorilla negra, el negro Antonio Cape y Antonio Portugués. Todos pasaron a ser posesión de Diego Ordoñez, sin embargo, éste también exigía a Hernando, a su hermana Marina, de siete años y con calidad de negra, y a su madre Giromar.

Al parecer, en el juicio la madre y la hermana no entraban en la defensa, sólo Hernando.

8 Murdo Macleod, Historia socioeconómica de la América Central española1520-1720, California, Universidad de California, 1989, 100 (Cuadro 11) 
Como ya se ha dicho, este joven mulato trabajaba en la estancia ganadera ubicada en la villa de la Trinidad, provincia de San Salvador; no obstante, él estaba enterado de que era libre, pues según el documento, Aldonça le había extendido una cédula donde le otorgaba la libertad. Sin embargo, Hernando Díaz, al parecer, quería permanecer con su familia y continuar dando sus servicio, este hecho fue utilizado como apelación por Diego Ordóñez, pues la petición de Hernando de permanecer en sus labores podía interpretarse como continuar siendo esclavo.

El mulato comenta que desde pequeño tenía conocimiento de su condición de liberto y que durante su estancia en la hacienda de doña Aldonça, donde trabajaba "poniendo herraduras al ganado”, fue llevado preso por orden de Gonzalo de Ovalle9.

Para defender al mulato, en el juicio se presenta el testamento de Aldonça, en el que ella asienta que desea otorgarle la libertad a Hernando Díaz de la Reguera. Pero este documento no era de mucha ayuda porque estaba sellado, pues según dictaban las leyes, se tenía que abrir a la muerte de Aldonça. Es entonces cuando el juez de la provincia de San Salvador, en este caso el alcalde mayor Pedro Giron de Alvarado, solicita que en el juicio se presenten los testigos de ambas partes.

Era común que los casos de liberación fueran poco atendidos, pero éste tuvo un excepcional seguimiento por parte de las autoridades locales y de la Audiencia. El proceso continúa con la muestra de pruebas y la interrogación de testigos. El defensor de Hernando Díaz, Pedro Ortiz de Zárate, presenta en su alegato el testamento de doña Aldonça.

Para los estudios afroamericanos son pocos los casos que se conocen acerca de los juicios no inquisitoriales sobre los esclavos de origen africano que tenían defensores, es decir, este documento representa un caso excepcional pues además el mulato no sólo tuvo un defensor (Pedro Ortiz de Zarate) sino que después de él continuó el caso Diego Ruiz.

Regresando al juicio, claro está que cómo no podían abrir el testamento, pues la autora (Aldonça) aún continuaba con vida, se presentaron a declarar los testigos que habían firmado el documento. De este modo, Pedro de Mendieta, Jorge Sosa y Lupe De Campo, además del mismo hermano de doña Aldonça Gaspar de Cepeda fueron llamados a declarar.

$9 \quad$ Este personaje era nieto de un conquistador del mismo nombre que había sido encomendero de la región de los Cuchumatanes, dueño de varios pueblos como: Tecpatán Puyumatlán (Santa Eulalia), Petatlán, Cacalutlán o Colutlán (¿Colotenango?), Ystapalapán (¿San Mateo Ixtatán?) y Jacaltenango. Ver: George Level, Conquista y cambio cultural. La sierra de los Chuchumatanes de Guatemala 1500-1820, CIRMA, 2000. 
Es importante advertir que el testigo Gaspar de Cepeda puede confundirse con el abuelo de Aldonça don Gaspar de Cepeda, quien era considerado como regidor perpetuo en la provincia de San Salvador. El testigo es en realidad el hijo de Isabel Costilla y Gómez Díaz de la Reguera. Era común que los nietos llevasen el nombre de sus abuelos, como lo muestra el caso de Gonzalo Ovalle, quien es hijo de Diego Ordóñez de Villaquirán, y sin embargo llevaba el nombre de su abuelo.

Los testigos aseguran que, en el testamento, Aldonça declaró "Hernando siempre ha sido libre y como tal ha vivido", además de que declaraba que le había dado la libertad por "cuestiones morales y de conciencia,” ya que su madre doña Isabel Costilla le había encargado a su muerte dicha tarea, y que por lo tanto ella estaba obligada a defender a Hernando Díaz.

El proceso continúa con un alegato sobre si al mulato esclavo se le reconoce su situación de liberto o si se le traslada a las haciendas de don Urbina. El juez determina que para que no continuara preso, Hernando fuera llevado a las haciendas en calidad de esclavo, mientras se solucionaba su situación.

Haciendo una pausa en el análisis del documento, se observa que Diego Ordóñez no tiene ganado el juicio. Las fechas arrojadas en las primeras 22 fojas son de marzo de 1589 a septiembre de 1590; en las siguientes fojas se puede ver que el juicio se retoma hasta el dos de enero de 1591. Entre septiembre y enero el mulato Hernando Díaz estuvo trabajando en la hacienda, y al parecer existieron algunos comportamientos de “rebeldía” que el defensor de Diego Ordóñez de Villaquirán, Agustín Ortiz, no pasó por alto. Este asunto fue determinante para que la defensoría de Ordóñez apelara y solicitara que el mulato continuara esclavo y fuera trasladado a Ciudad Real de Chiapa.

Varios testigos fueron presentados ante el juez y después de haber jurado decir la verdad, revelaron el “comportamiento rebelde” del Hernando Díaz. Entre ellos se encontraban Francisco del Lungara [sic] y Juan de Sant. Atestiguaron contra Hernando Díaz argumentando que, en la hacienda, el mulato había tenido "un comportamiento rebelde y que había huido de dicha hacienda".

Recordemos que los negros que huían de las haciendas eran considerados como cimarrones, y cuando eran reducidos o capturados y trasladados a la hacienda de origen, eran fuertemente castigados, como ejemplo para los demás esclavos. Seguramente Hernando Díaz recibió el castigo acostumbrado, sin embargo en la visión de los españoles, el mejor castigo era que 
volviese a ser esclavo y que continuara trabajando en las haciendas.

Agustín Ortiz, apeló ante el juez que ante los licitados pide que se le entregue al mulato para trasladarlo a Chiapa, desconociendo las cláusulas que se habían emitido a favor de Hernando Díaz. Sin embargo, el juez determina que no proceden los argumentos y que continuará el juicio. Pero advierte que el proceso ya tiene varios años y que ha costado más de lo que vale el esclavo, pues hasta el momento los gastos ya son muchos: tan sólo para pagar a los escribanos y el papel -que en esa época era importado de Europa-se había gastado una cantidad aproximada de dos mil pesos de oro común. Por lo que el mismo juez determina que con ese dinero bien se podría comprar otro esclavo a un precio más bajo.

Haciendo un análisis de los documentos hallados en el Archivo General de Centro América ${ }^{10}$, el promedio de compra de un esclavo hombre es de 367 pesos; mientras que el de la mujer es de 398 pesos; por lo que los argumentos del juez eran válidos. Ante esta situación se debe analizar por qué el interés de Diego Ordóñez de Villaquirán por continuar con el procesos jurídico en torno a la libertad del mulato.

¿Acaso Diego Ordóñez de Villaquirán tenía una rivalidad con su esposa Aldonça por la situación del mulato? ¿Aldonça apoyó a Hernando Díaz por ser su primo o sólo por que tenía un compromiso moral con su madre?

No estamos obligados a responder estas preguntas, sin embargo, según se puede observar en el documento; por la ayuda que otorgó Aldonça y por haber pagado su parte en el juicio -que fue de 1200 pesos de oro común-, es evidente que su “conciencia” iba más allá del compromiso con su madre Isabel Costilla. Como ya se ha mencionado, Hernando Díaz era hijo de Diego Díaz de la Reguera, tío de Aldonça, y el mulato siempre fue tratado como libre. Seguramente la relación entre los primos fue estrecha y por ello decidió invertir tanto dinero para que pudiera salir de la cárcel. En el manuscrito no determinan el pago de la fianza, pero se menciona que se saldó.

Sin embargo, los esfuerzos realizados por la defensa de Hernando se veían obtaculizados por la contraparte, pues Pedro Ortiz, defensor de Ordóñez, también daba dinero para las contrademandas, para apelar los juicios y fue por ello que el proceso se alargo tanto.

Mientras la lucha entre Aldonça y Ordóñez, o bien entre Zarate y Ortiz, se llevó a cabo en el juzgado; la situación e Hernando Díaz fue muy difícil, su estancia en la cárcel, en la hacienda, su

10 Se revisó la sección de protocolos de 1550 a 1540. Ver mi tesis de licenciatura, Esclavitud y libertad de la población africana en el Chiapas colonial 1540-1640. México, Universidad Nacional Autónoma de México. 2007. 
huída, su captura, los castigos recibidos por su intento de escape y su vuelta a la cárcel, fueron sufridos durante los tres años que vivió el proceso.

El discurso de Hernando emitido en el manuscrito siempre es contestatario, todo el tiempo estuvo conciente de que era libre y que tenía una posición si no económica, sí social, pues al ser reconocido por su padre, Diego Díaz de la Reguera, de quien llevaba el mismo apellido, tenía cierta posición. ¿Por qué no utilizó esta posición? Seguramente era difícil separarse de su familia, pues hay que recordar que su madre Giromar y su hermana Marina, aún continuaban siendo esclavas. Él luchaba por su libertad, pues con ella podía lograr acceder a algún gremio, o poder trabajar para comprar la libertad de su familia y de esto era conciente Aldonça, por ello la defensa tan álgida.

. El juez dicta sentencia: declara libre a Hernando Díaz por las pruebas presentadas, entre las que destaca el testimonio de doña Aldonça ante el juez, los testigos son aceptados como ya se mencionó. Aldonça afirma que fue presionada por Ordóñez, su esposo, para revocar su declaración; sin embargo, ella jura que es verdad que existe una cédula donde le otorga la libertad a Hernando.

El pleito no termina, pues Diego Ordóñez de Villaquirán comienza un proceso de contrademanda y varios autos con la finalidad de que "se le devuelva a su esclavo". A pesar de ello, no logra su objetivo y es sentenciado por el juez a que, si vuelve a presentar otra demanda, puede ser preso por no obedecer la ley.

\section{Conclusiones}

El presente documento es un ejemplo elocuente de una de las formas de liberación que el esclavo tuvo que buscar para obtener su libertad. Hernando tenía todo el apoyo de su ama y eso le valió para conseguirla, pero muchos esclavos no tuvieron la misma fortuna. Además se debe tomar en cuenta que se trata de un mulato que contaba con el respaldo de su familia, a diferencia de su madre y hermana, quienes no lograron obtener la libertad, pues Diego Ordóñez se amparó para que no le pudieran quitar sus propiedades, entre ellas las dos esclavas. 